Erratum: Analytical Sciences, 2016, Vol. 32, No. 2, p. 167

\title{
Simultaneous Quantification of Iodine and Other Elements in Infant Formula by ICP-MS Following an Acid Digestion with Nitric Acid and Hydrogen Peroxide
}

\author{
Koji FujISAKI, ${ }^{\dagger}$ Hiroshi Matsumoto, Yukiko ShImoKaWa, and Kenji KIYOTAKI
}

Analytical Research Center, Morinaga Milk Industry Co., Ltd., 5-1-83 Higashihara, Zama, Kanagawa 252-8583, Japan

On page 168 , the left column, line 26 to 29 , the sentence,

Working standard solutions $\left(1,5,7.5\right.$, and $\left.10 \mathrm{ng} \mathrm{mL}^{-1}\right)$ were prepared from the iodine stock solution by dilution with $7.0 \%$ $\left(\mathrm{v} \mathrm{v}^{-1}\right)$ nitric acid, 5.0\% $\left(\mathrm{v} \mathrm{v}^{-1}\right)$ acetic acid and 1.2\% $\left(\mathrm{v} \mathrm{v}^{-1}\right)$ hydrogen peroxide.

should read

Working standard solutions $\left(1,5,7.5\right.$, and $\left.10 \mathrm{ng} \mathrm{mL}^{-1}\right)$ were prepared from the iodine stock solution by dilution with $7.0 \%$ $\left(\mathrm{v} \mathrm{v}^{-1}\right)$ nitric acid and 5.0\% $\left(\mathrm{v} \mathrm{v} \mathrm{v}^{-1}\right)$ acetic acid. 